\title{
Analysis and Comparison of Long-Distance Pipeline Failures
}

\author{
Lianshuang Dai, ${ }^{1,2}$ Dongpo Wang, ${ }^{1}$ Ting Wang, ${ }^{3}$ Qingshan Feng, ${ }^{2}$ and Xinqi Yang ${ }^{1}$ \\ ${ }^{1}$ School of Materials Science and Engineering, Tianjin University, Tianjin 300072, China \\ ${ }^{2}$ PetroChina Pipeline Company, Langfang, Hebei 065000, China \\ ${ }^{3}$ PetroChina Pipeline R\&D Center, Langfang, Hebei 065000, China
}

Correspondence should be addressed to Dongpo Wang; wangdp@tju.edu.cn

Received 20 February 2017; Revised 17 April 2017; Accepted 3 May 2017; Published 25 May 2017

Academic Editor: Merv Fingas

Copyright (C) 2017 Lianshuang Dai et al. This is an open access article distributed under the Creative Commons Attribution License, which permits unrestricted use, distribution, and reproduction in any medium, provided the original work is properly cited.

\begin{abstract}
The analysis results of long-distance oil and gas pipeline failures are important for the industry and can be the basis of risk analysis, integrity assessment, and management improvement for pipeline operators. Through analysis and comparison of the statistical results of the United States, Europe, the UK, and PetroChina in pipeline failure frequencies, causes, consequences, similarities, and differences of pipeline management, focusing points and management effectiveness are given. Suggestions on long-distance pipeline safety technology and management in China are proposed.
\end{abstract}

\section{Introduction}

It is important to maintain high-pressure oil and gas pipeline systems safety and reliability, because the products are hazardous and may result in fire, explosion, and poisoning and lead to significant economic losses, casualties, and environmental pollution [1-3]. By collecting and analyzing the failure data, pipeline operators can find out the causes of failure events and understand the weak point in pipeline management which is significant for pipeline risk identification, integrity assessment, risk mitigation, and accident prevention [4-6].

Statistical results of the US, Europe, the UK, and PetroChina in pipeline failure frequencies, causes, and consequences are comparatively analyzed. Similarities and differences of pipeline management are given. Suggestions on long-distance pipeline safety technology and management in China are proposed.

\section{Analysis and Comparison}

Failure statistical results of PHMSA in the US [7], EGIG in Europe [8], UKOPA in UK [9], and PNGPC in China on long-distance pipeline failure frequencies, causes, and consequences are comparatively analyzed. Table 1 shows the pipeline types that the analysis involves.
2.1. PHMSA. Failure data of all pipelines in the US is updated to show the recent 20 years' statistical results and detailed information by PHMSA. Significant incidents of onshore pipelines (for liquid, only crude oil and refined and/or petroleum product are involved; for gas, only transmission line is involved) are filtered from the database and calculated for the failure frequencies in this paper. Significant incidents are those including any of the following conditions:

(1) Fatality or injury requiring in-patient hospitalization.

(2) $\$ 50,000$ or more in total costs, measured in 1984 dollars.

(3) Highly volatile liquid releases of 5 barrels or more or other liquid releases of 50 barrels or more.

(4) Liquid releases resulting in an unintentional fire or explosion.

2.1.1. Failure Frequency. Figure 1 shows that from 2004 to 2015, failure frequencies of oil pipelines in the US vary between 0.4 times $/ \mathrm{kkm} \cdot \mathrm{yr}$ and $0.6 \mathrm{times} / \mathrm{kkm} \cdot \mathrm{yr}$, which is slightly increasing in the last 5 years as seen in the trend line. As for the natural gas pipelines shown in Figure 2, the number goes up from $0.04 \mathrm{times} / \mathrm{kkm} \cdot \mathrm{yr}$ to $0.14 \mathrm{times} / \mathrm{kkm} \cdot \mathrm{yr}$ with vibration. 
TABLE 1: Mediums included in the statistical data.

\begin{tabular}{|c|c|c|c|c|}
\hline \multirow{2}{*}{ NO. } & \multirow{2}{*}{ Organization/Company } & \multicolumn{3}{|c|}{ Pipeline Medium } \\
\hline & & Crude Oil & Product Oil & Natural Gas \\
\hline 1 & PHMSA & $r$ & $\checkmark$ & $\checkmark$ \\
\hline 2 & EGIG & & & $\checkmark$ \\
\hline 3 & UKOPA & & & $\checkmark$ \\
\hline 4 & PNGPC & $\checkmark$ & $\checkmark$ & $\checkmark$ \\
\hline
\end{tabular}

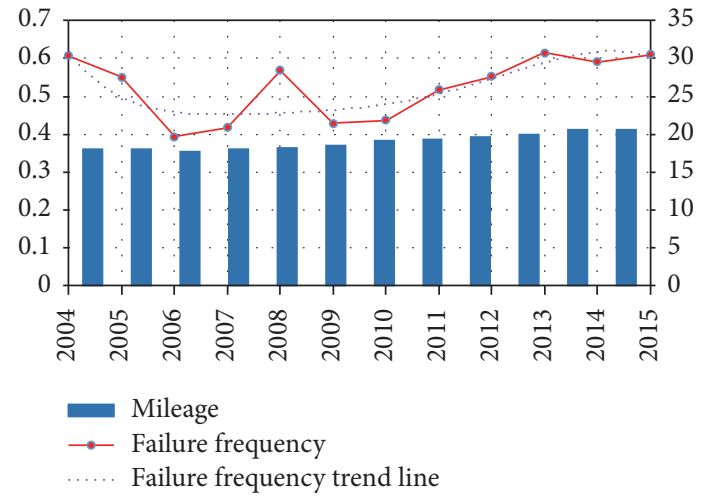

FIGURE 1: Mileage and failure frequency for oil pipelines.

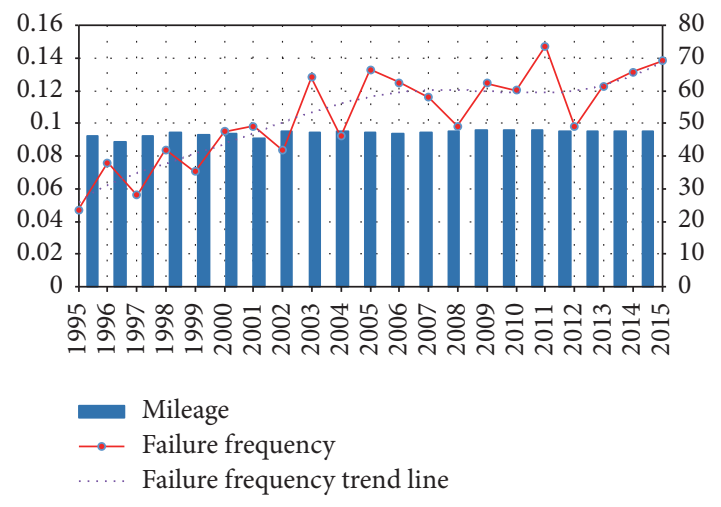

FIGURE 2: Mileage and failure frequency for gas pipelines.

2.1.2. Failure Causes. Based on the statistical results from 2010 to 2015, which includes 432 oil pipeline failures and 238 gas pipeline failures, all of which are flagged as significant incidents in the database, the top 3 causes for oil pipeline failures are corrosion, pipe/weld material failure, and equipment failure, while those of gas pipeline failures are pipe/weld material failure, excavation damag, and corrosion (see Figures 3 and 4).

Table 2 listed the causes and subcauses categorized by PHMSA.

(1) Corrosion. For liquid pipelines, corrosion is the most important factor for failure, while, for gas pipelines, corrosion is the top 3 of all failure factors. Among those, external corrosion usually accounted for more than 60\%, mainly

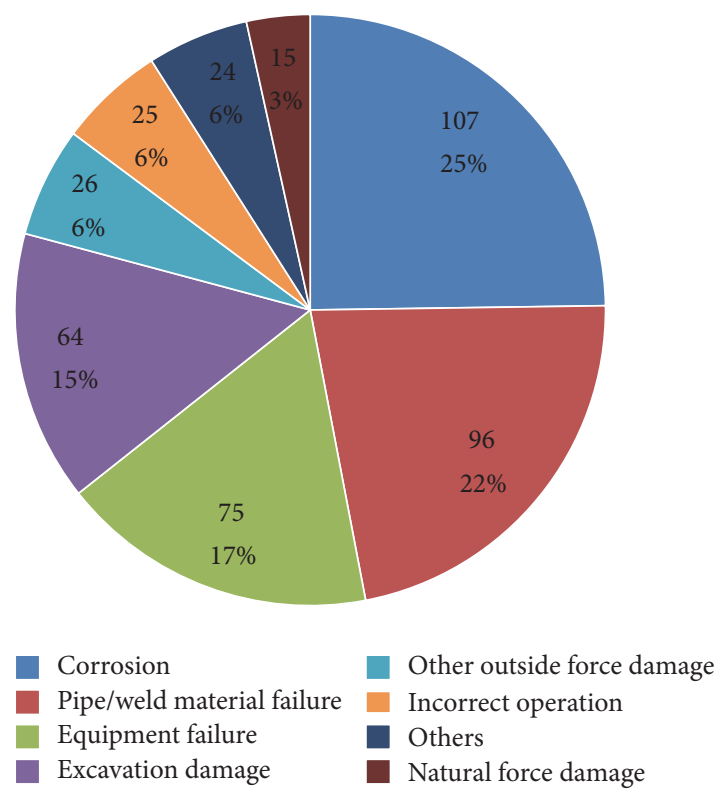

FIGURE 3: Oil pipelines causes.

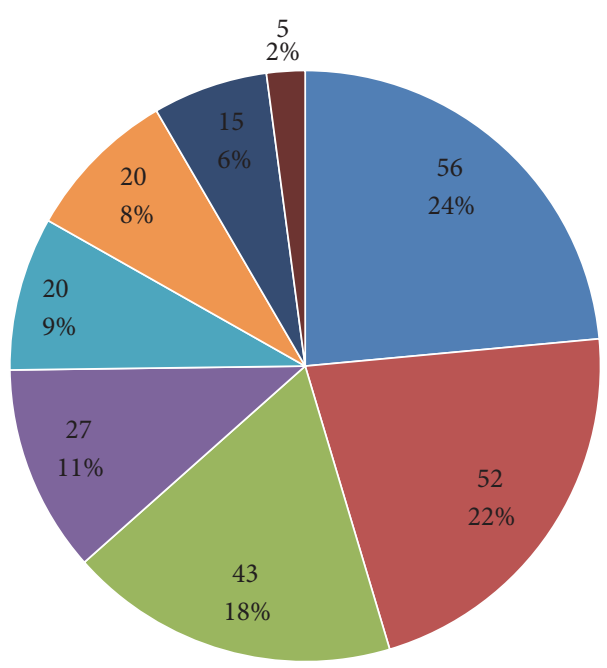

Pipe/weld material failure

Excavation damage

Corrosion

Equipment failure

Natural force damage

Other outside force damage

Others

Incorrect operation

Figure 4: Gas pipelines causes. 
TABLE 2: Causes and sub-cause categried by PHMSA.

\begin{tabular}{|c|c|c|}
\hline NO. & Causes & Sub-causes \\
\hline \multirow{3}{*}{1} & Corrosion & \\
\hline & External Corrosion & $\begin{array}{l}\text { Galvanic Corrosion, Stray Corrosion, Microbiological Corrosion, Selective } \\
\text { Seam Corrosion,... }\end{array}$ \\
\hline & Internal Corrosion & Corrosive Commodity, Acid Water, Microbiological Corrosion, Erosion, ... \\
\hline \multirow{4}{*}{2} & Pipe/Weld Material Failure & \\
\hline & Construction, Installation or Fabrication Related & Weld Quality, Mechanical Damage in the Field, ... \\
\hline & Original Manufacturing Related & Weld Quality, Manufacturing Defect, ... \\
\hline & Environmental Related & Stress Corrosion Cracking, Deformation Related Cracking, ... \\
\hline \multirow{4}{*}{3} & Excavation Damage & \\
\hline & Operator's Contractor (Second Party) & $\begin{array}{l}\text { Excavation Practices not Sufficient, Locating Practices not Sufficient, } \\
\text { Previous Damage, ... }\end{array}$ \\
\hline & Third Party & $\begin{array}{l}\text { Excavation Practices not Sufficient, Locating Practices not Sufficient, } \\
\text { One-call Notification Practices not Sufficient, One-call Notification Center } \\
\text { Error,... }\end{array}$ \\
\hline & Previous Damage due to Excavation Activity & One-call Notification Practices not Sufficient, Previous Damage, ... \\
\hline 4 & Natural Force Damage & Earth Movement, Heavy Rains/Floods, Lighting, Temperature, ... \\
\hline 5 & Incorrect Operation & $\begin{array}{l}\text { Damage by Operator or Operator's Contractor, Pipeline or Equipment } \\
\text { Overpressure, Equipment not Installed Properly, ... }\end{array}$ \\
\hline 6 & Other Outside Force Damage & Damage by Cars, Boats, Nearby Industry or Fire/Explosion, ... \\
\hline
\end{tabular}

galvanic corrosion, while internal corrosion is mainly of microbiological corrosion.

(2) Pipe/Weld Material Failure. If the failure incidents for oil and gas pipelines are analyzed together, pipe/weld material failure is the top 1 factor. For subcauses that are analyzed, construction related (including field welded girth weld, backfill dent, etc.) accounts for more than $50 \%$.

(3) Excavation Damage. Excavation damage is another important cause for oil and gas pipeline failures in the US, which accounts for $15 \%$ for oil pipeline failures and $22 \%$ for natural gas pipeline failures. Among those, the third party excavation damage accounts for the largest percentage, mainly due to the usage of one-call (excavation call system) system and the insufficient excavation practices.

(4) Natural Force Damage. In this cause, earth movement and heavy rain/flood are the main factors.

2.1.3. Failure Consequences. During 2004 to 2015, numbers of casualties and property loss caused by pipeline accidents in the US did not vary significantly, except the peak value in 2010 (see Figure 5), which is because of the rupture fire of the Pacific Gas and Electric Company's pipeline and rupture leakage of Enbridge $6 \mathrm{~B}$ crude oil pipeline.

The property loss includes estimated cost of public and nonoperator private property damage, product released intentionally or unintentionally, operator's property damage and repairs, operator's emergency response, and environmental remediation.

2.2. EGIG. Up to 2013, the total length of EGIG gas pipeline becomes $144 \mathrm{kkm}$. The objective of EGIG is to collect and

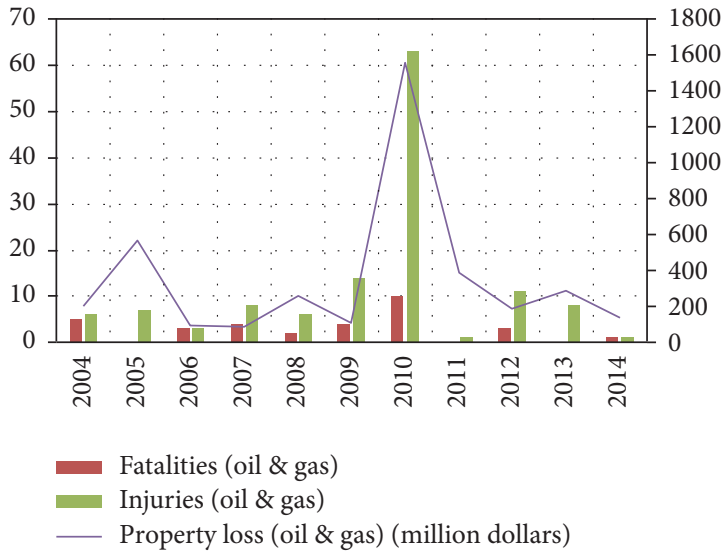

FIGURE 5: Failure consequences in the US reported by PHMSA.

present data on loss of gas incidents in order to present the safety performance of the European gas transmission network to the general public and authorities.

The required criteria for an incident to be recorded in the EGIG database are the following:

(1) The incident must lead to an unintentional gas release.

(2) The pipeline must fulfil the following conditions:

(a) to be made of steel,

(b) to be onshore,

(c) to have a maximum operating pressure higher than 15 bar,

(d) to be located outside the fences of the gas installations. 


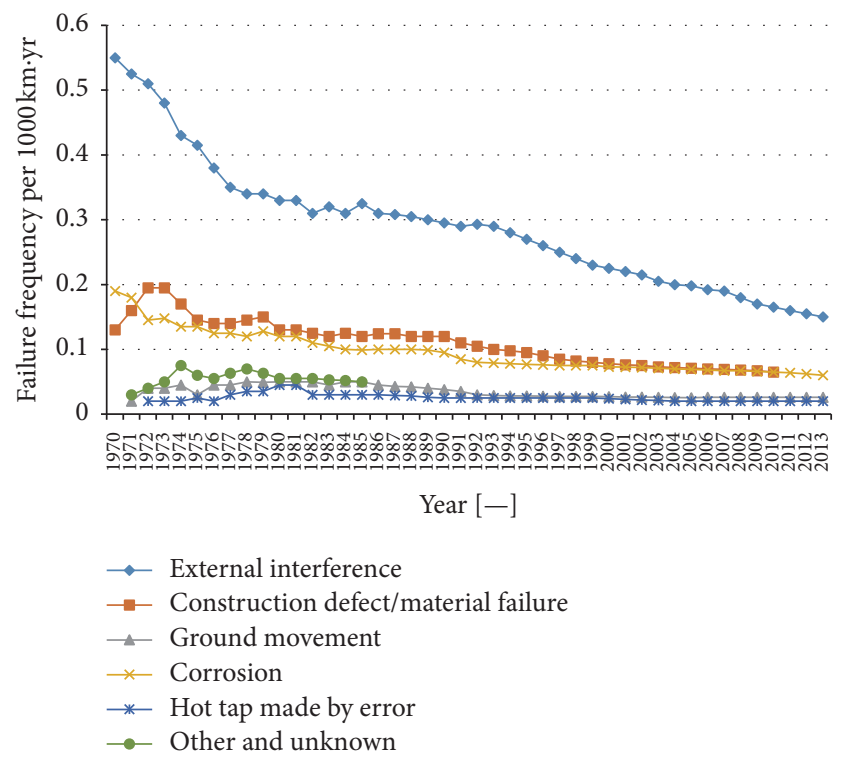

FIGURE 6: Failure frequencies of different causes by EGIG.

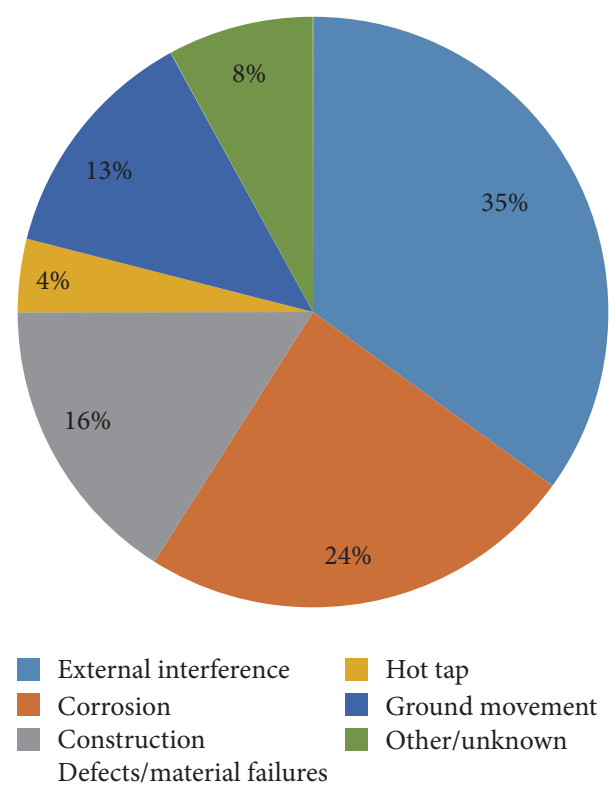

Figure 7: Failure causes by EGIG.

2.2.1. Failure Frequency. From 1970 to 2013, the primary failure frequencies for the entire period (up to the year) per cause keep decreasing (See Figure 6).

In 2013, the primary failure frequency over the entire period (1970-2013) was equal to 0.33 per $\mathrm{kkm} \cdot \mathrm{yr}$. This is slightly lower than the failure frequency of $0.35 \mathrm{per} \mathrm{kkm} \cdot \mathrm{yr}$ reported in the 8th EGIG report (1970-2010). The primary failure frequency over the last five years was equal to 0.16 per $\mathrm{kkm} \cdot \mathrm{yr}$, showing an improved performance over recent years.

2.2.2. Failure Causes. Top 3 causes for gas pipeline failures in EGIG are external interference, corrosion, and construction defects/material failure (see Figure 7).

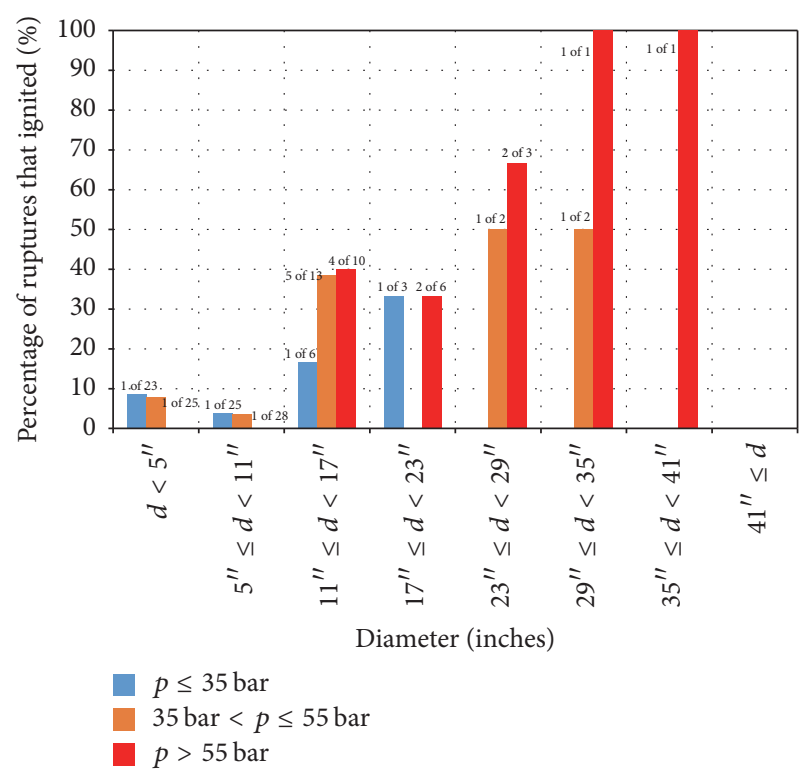

FIgURE 8: Ignited failures analysis by EGIG.

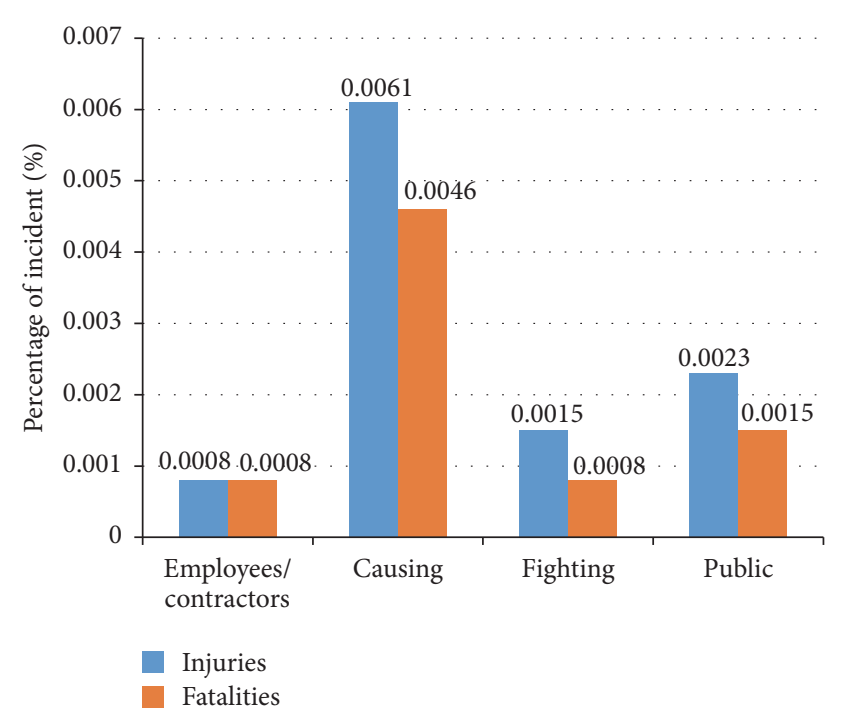

FIGURE 9: Casualties' analysis by EGIG.

2.2.3. Failure Consequences. According to statistical results, in period of 1970-2013, only $5.0 \%$ of the gas releases recorded in the EGIG database ignited. Gas releases from large diameter pipelines at high pressure have ignited more frequently than smaller diameter pipelines at lower pressure (see Figure 8).

The highest fatality and injury rate can be found among the people who are directly involved in causing the incident. Eight cases $(0.61 \%$, total 1309$)$ caused fatalities among the people causing the incident (see Figure 9).

2.3. UKOPA. Up to 2014 , the total length of UKOPA pipeline becomes $22.4 \mathrm{kkm}$. A product loss incident is defined in the context of this report as 


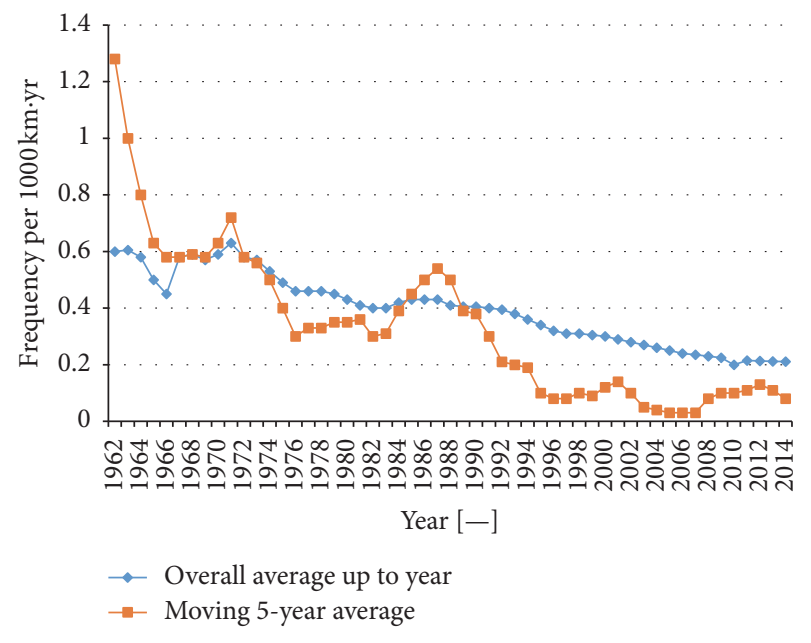

Figure 10: Average failure frequencies by UKOPA.

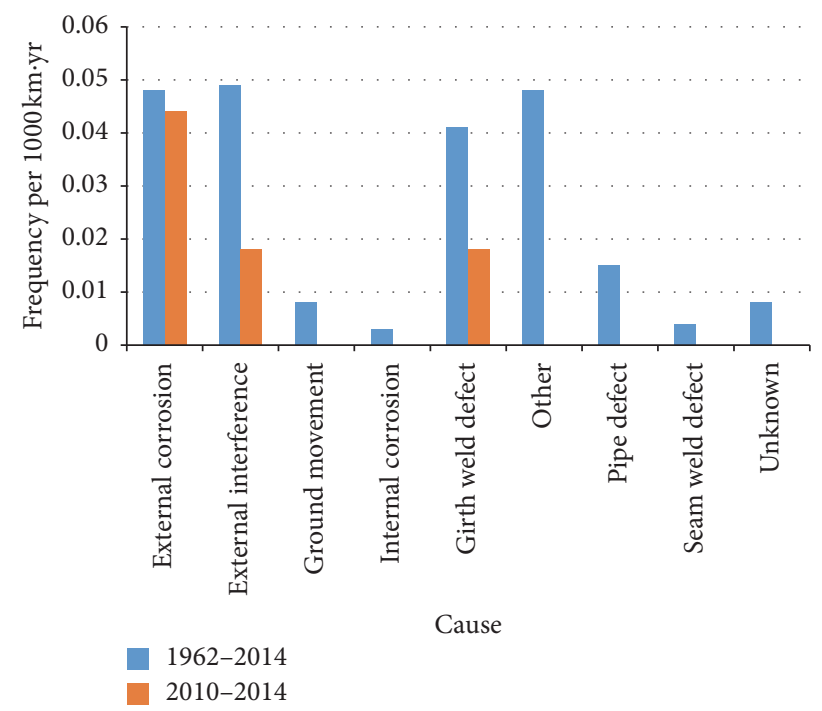

FIGURE 11: Failure causes by UKOPA.

(1) an unintentional loss of product from the pipeline,

(2) within the public domain and outside the fences of installations,

(3) excluding associated equipment (e.g., valves, compressors) or parts other than the pipeline itself.

2.3.1. Failure Frequency. From 1962 to 2014, altogether 192 leakages have been recorded. The overall failure frequency over the period 1962 to 2014 is 0.219 incidents per $\mathrm{kkm} \cdot \mathrm{yr}$, while in the previous report this figure was 0.223 incidents per $\mathrm{kkm} \cdot \mathrm{yr}$ (covering the period from 1962 to 2013). The overall trend continues to show a reduction in failure frequency (see Figure 10).

2.3.2. Failure Causes. The top 3 failure causes of UKOPA are external corrosion, external interference, and girth weld defects (see Figure 11).
TABLE 3: Ignited failures analysis by UKOPA.

\begin{tabular}{lcc}
\hline $\begin{array}{l}\text { Affected } \\
\text { Component }\end{array}$ & Cause Of Fault & Hole Diameter Class \\
\hline Pipe & Seam Weld Defect & $0-6 \mathrm{~mm}$ \\
Pipe & Ground Movement & $\begin{array}{c}\text { Full Bore and Above } \\
\left(18^{\prime \prime} \text { Diameter pipe }\right)\end{array}$ \\
Pipe & Girth Weld Defect & $6-20 \mathrm{~mm}$ \\
Pipe & Unknown & $6-20 \mathrm{~mm}$ \\
Pipe & Pipe Defect & $0-6 \mathrm{~mm}$ \\
Pipe & Unknown & $40-110 \mathrm{~mm}$ \\
Pipe & Lightning Strike & $0-6 \mathrm{~mm}$ \\
Bend & Internal Corrosion & $0-6 \mathrm{~mm}$ \\
Bend & Pipe Defect & $6-20 \mathrm{~mm}$ \\
\hline
\end{tabular}

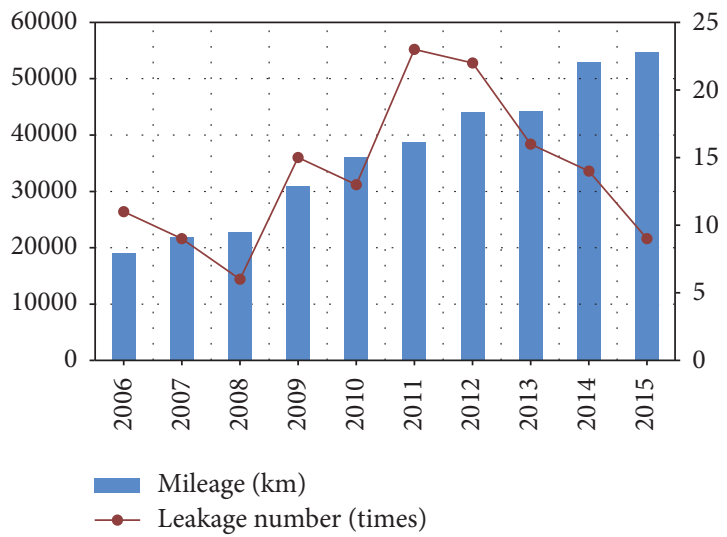

FIGURE 12: Mileage and failure numbers for PNGPC pipelines.

2.3.3. Failure Consequences. There were 9 out of 192 (4.7\%) product loss incidents that resulted in ignition. However, there is no obvious conclusion, as shown in Table 3.

2.4. PNGPC. Up to 2015, the total length of PNGPC longdistance pipeline becomes $53 \mathrm{kkm}$. Failure data were filtered in order to be comparable with other countries. Only unintentional leakages for crude oil, refined oil, and natural gas for transmission lines are counted here.

2.4.1. Failure Frequency. Failure frequency has increased before 2011 and decreased in recent 5 years (see Figures 12 and 13).

2.4.2. Failure Causes. During 2006 to 2015, altogether 134 leakages have been recorded, among which, illegal tap, manufacturing defects, and construction quality are the top 3 causes (see Figure 14).

(1) Illegal Tap. With the enhancement of legislation, failure of this cause has a significant downward trend.

(2) Manufacturing Defect. The majority of failures belonging to this cause are due to spiral weld defects, which is 


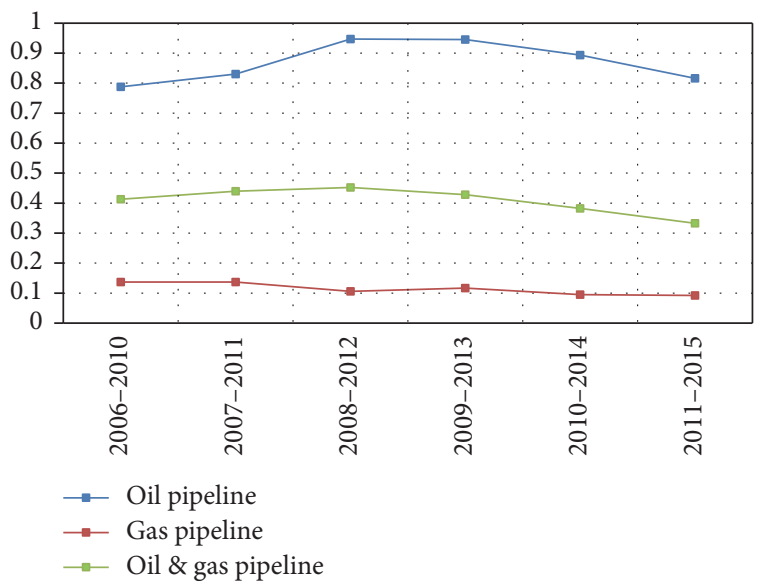

Figure 13: Average failure frequencies by PNGPC.

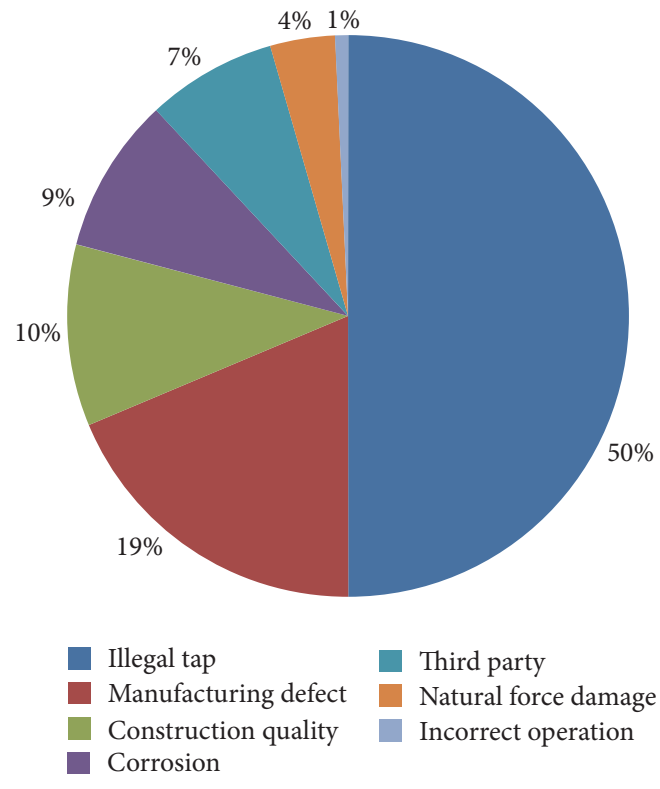

FIGURE 14: Failure causes by PNGPC.

significantly decreasing as the manufacturing quality improved and the vintage pipelines abandoned.

(3) Construction Quality. This mainly includes girth weld defects, gouges, and dents. As the decreasing of illegal tap and manufacturing defects and also the well-controlled corrosion, construction quality becomes the top concerned factor in China now.

(4) Corrosion. As for the abandonment of old pipelines and all kinds of control methods, including periodic in-line inspection, corrosion is not as serious as before. However, pin-hole corrosions still cause failures, which are hardly detected by MFL.

(5) Third Party. This is mainly due to the supervision escaping, with unauthorized construction of third party, which

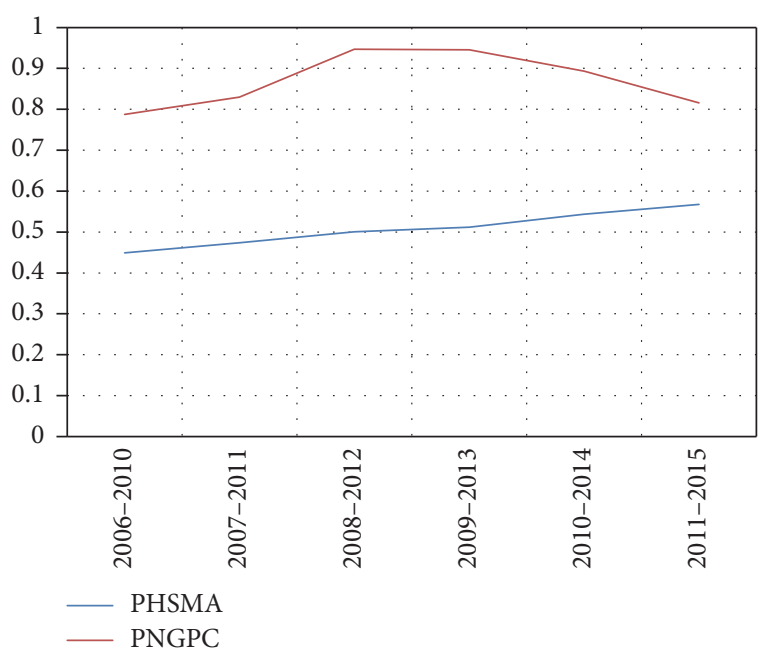

FIgURE 15: Compared failure frequencies for oil pipelines.

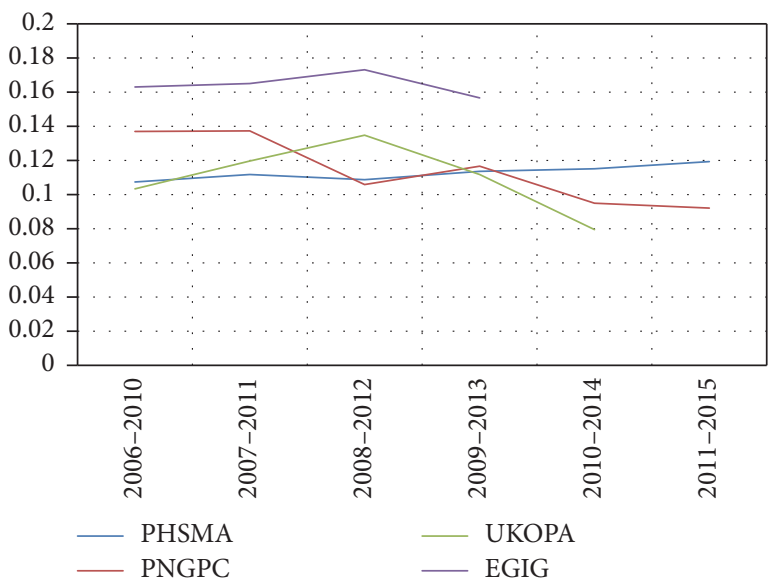

FIgURE 16: Compared failure frequencies for gas pipelines.

causes damage on the pipes. As third party constructions mostly happen in the economically active regions, consequences are relatively serious.

\section{Analysis Result Comparisons}

Investigation and referring to foreign related failure statistics can provide good experience for domestic pipeline operators, while figuring out their own management level for continuous improvement.

3.1. Failure Frequencies. Compared with the failure frequencies (5 years' moving average) at home and abroad in the past 10 years, the value of PNGPC's oil pipelines is higher than that of the US, while that of PNGPC's gas pipeline is roughly at the same level compared to the US and slightly lower than the European (see Figures 15 and 16). 


\subsection{Failure Causes}

(1) Illegal Tap. Restricted by the current situation of China's social and economic development, this cause becomes China's top 1 factor of pipeline failure during the last 10 years, which rarely happens in the US and Europe. However, with the strengthening of legislation and publicity, the frequency is significantly reduced.

(2) Pipe/Weld Material Failure (Manufacturing Defect and Construction Defect). This factor leads to a higher proportion of failures both at home and abroad. With the promotion of technology and quality management, defects on pipe bodies can be effectively controlled. However, due to various constraints, it is difficult to guarantee the construction quality. Hence, girth weld defects, dents, gouges, and other defects will still exist to certain degrees.

(3) Corrosion. As for the abandonment of vintage pipelines and the promotion of integrity management, corrosion failures are effectively controlled, which is still one of the main factors of failures generally.

(4) Third Party. Failures due to this factor always occur in economically active areas between urban and rural both at home and abroad. As for pipeline patrolling in the US and Europe is not as timely and intensive as in China, the proportion of failure caused by this factor is slightly higher than that of China.

3.3. Failure Consequences. Compared with foreign countries, failure consequence data is quite deficient in China. Only the consequences of serious pipeline accidents will be recorded, including casualties, economic losses, and leakage.

\section{Conclusions and Suggestions}

As for the concern from government and public on pipeline safety in China, management has been significantly improved by operators. Consequently, frequency of pipeline failures is decreasing. According to the statistical results, PNGPC is not very far compared with foreign countries. There are still some aspects both in technology and in management that should be improved, such as quality of manufacture and construction of pipeline and third party monitoring.

\section{Nomenclature}

PHMSA: Pipeline and Hazardous Materials Safety Administration

EGIG: European Gas Pipeline Incident Data Group

UKOPA: United Kingdom Onshore Pipeline Operators' Association

PNGPC: PetroChina Natural Gas \& Pipeline Company.

\section{Conflicts of Interest}

The authors declare that there are no conflicts of interest regarding the publication of this paper.

\section{Acknowledgments}

Preparation of this paper was supported by the PNGPC; this is gratefully acknowledged by coauthors Dongpo Wang, Ting Wang, Qingshan Feng, and Xinqi Yang. Thanks are also due to numerous past and present colleagues for insights and helpful discussions.

\section{References}

[1] P. Hopkins, "Transmission pipelines: how to improve their integrity and prevent failures," in Pipeline Technology, Proceedings of the 2nd international pipeline technology conference, $\mathrm{R}$. Denys, Ed., vol. 1, pp. 683-702, 1995.

[2] W. Y. Zheng, "Stress corrosion cracking of oil and gas pipelines in near neutral pH environment: Review of recent research," Energy Materials: Materials Science and Engineering for Energy Systems, vol. 3, no. 4, pp. 220-226, 2008.

[3] T. Wang, W. Xuan, X. Wang et al., "Overview of oil and gas pipeline failure database," in Proceedings of International Conference on Pipelines and Trenchless Technology, ICPTT 2013, pp. 1161-1167, chn, October 2013.

[4] H. L. Li, X. W. Zhao, and L. K. Ji, "Oil and gas pipeline failure analysis and integrity management," Testing - Physical Volume, pp. 24-31, 2005.

[5] R. Singh, Pipeline Integrity Handbook: Risk Management and Evaluation, vol. 51, Gulf Professional Publishing, UK, 2014.

[6] C. R. F. Azevedo, "Failure analysis of a crude oil pipeline," Engineering Failure Analysis, vol. 14, no. 6, pp. 978-994, 2007.

[7] PHMSA, http://primis.phmsa.dot.gov/comm/reports/safety/PSI .html. 2015.

[8] EGIG, "9th report of the gas pipeline incidents of european gas pipeline incident data group," 2015.

[9] UKOPA, "UKOPA pipeline product loss incidents and faults report (1962-2014)," 2015. 


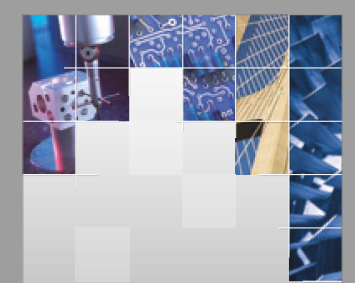

\section{Enfincering}
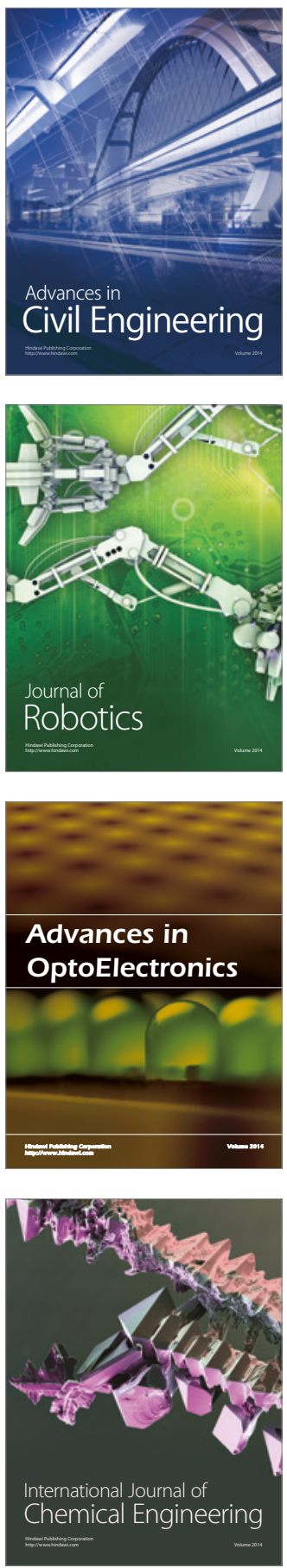

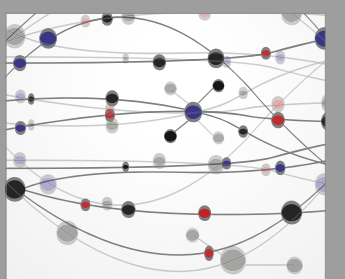

The Scientific World Journal

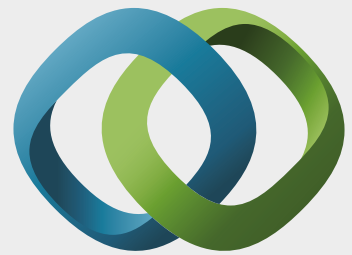

\section{Hindawi}

Submit your manuscripts at

https://www.hindawi.com
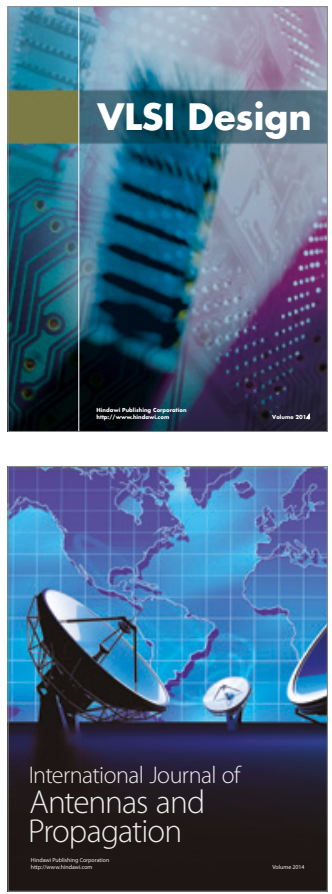

\section{Rotating}

Machinery
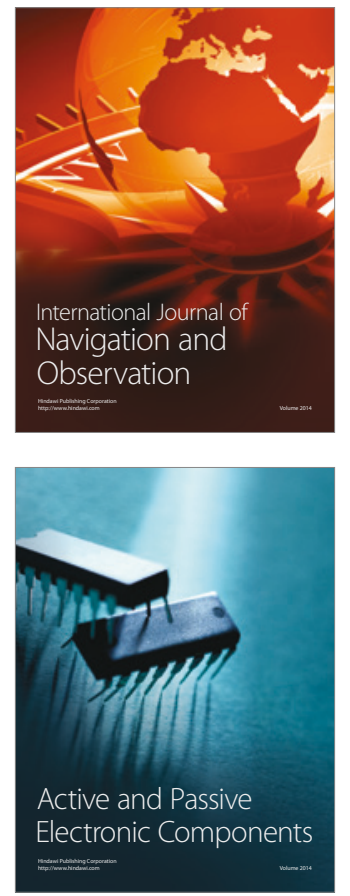
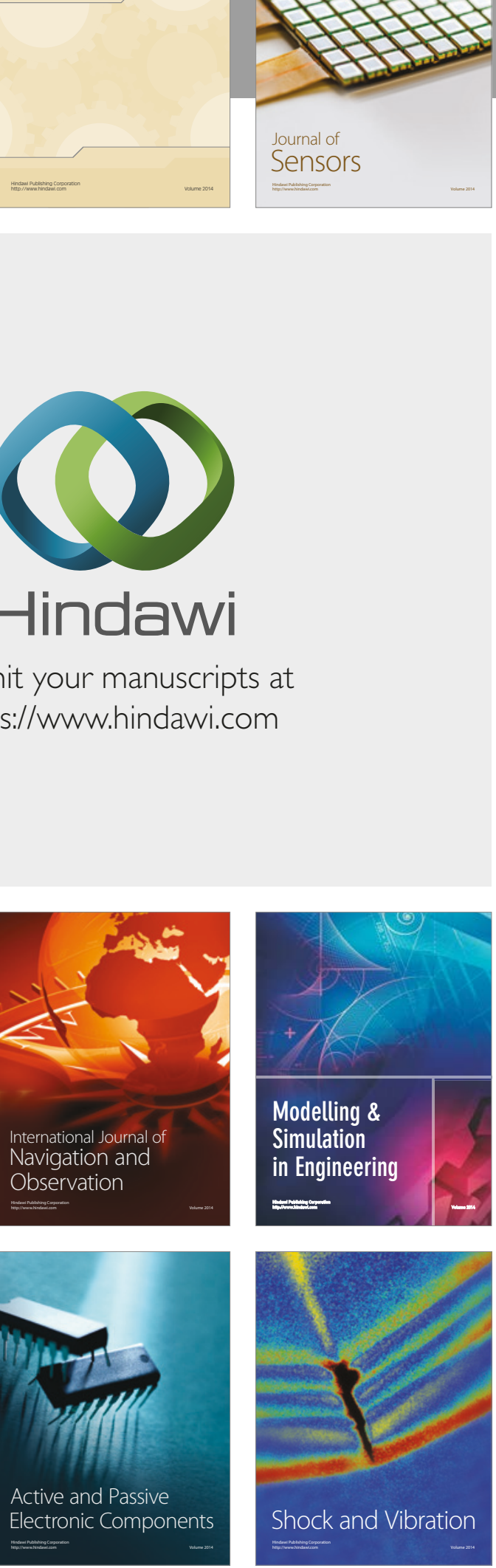
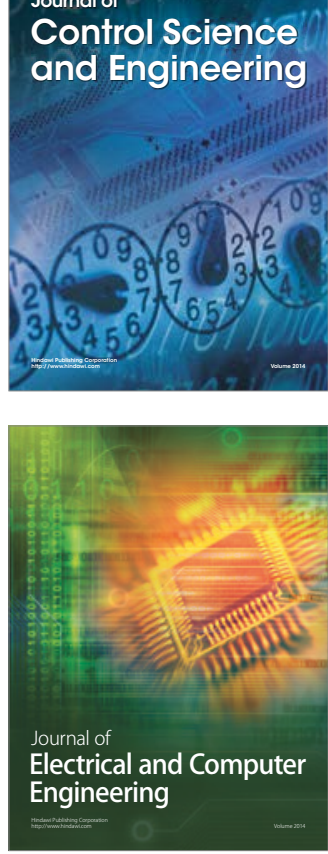

Distributed

Journal of

Control Science

and Engineering
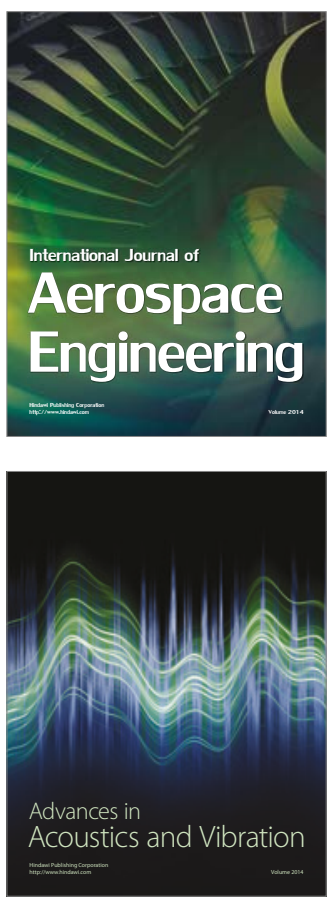

Sensor Networks 